\title{
Collaborative practices from health care teams to face the covid-19 pandemic
}

\author{
Práticas colaborativas em equipe de saúde diante da pandemia de COVID-19 \\ Prácticas colaborativas en equipo de salud ante la pandemia del COVID-19
}

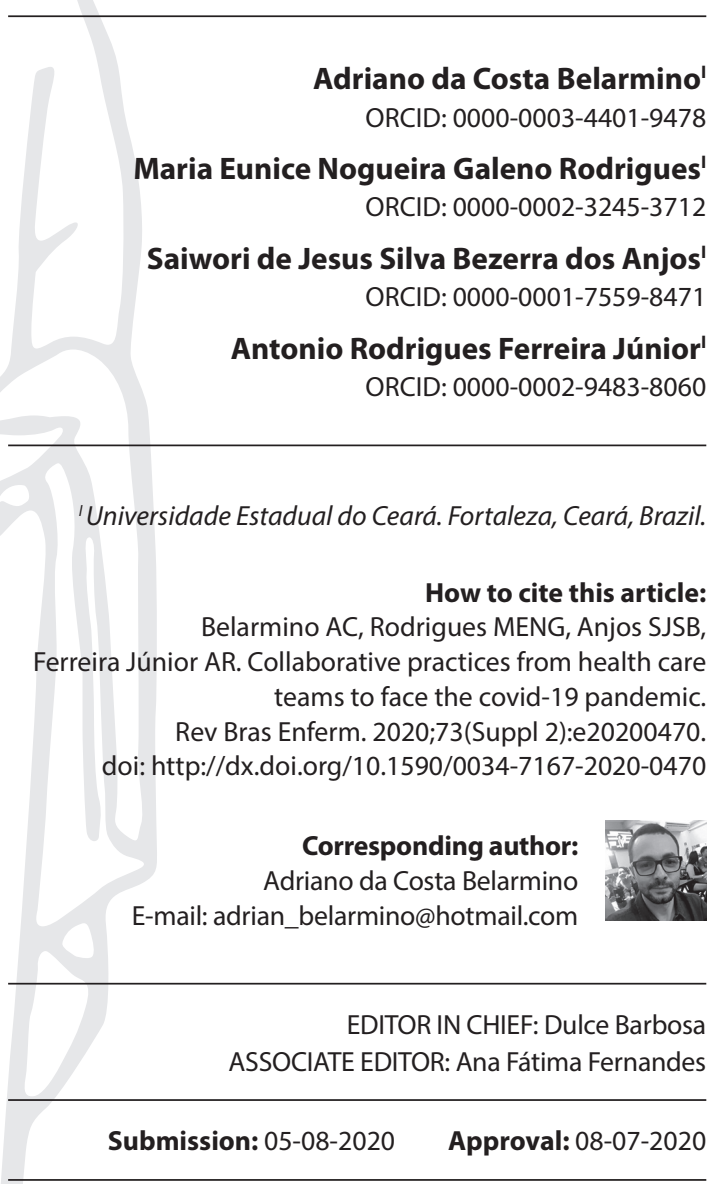

\section{ABSTRACT}

Objective: To report the experience of collaborative practices facing the COVID-19 pandemic. Methods: This is a report about the experience of collaborative practices conducted by health care teams in emergency service in the Emergency Care Units facing of COVID-19 pandemic in the city of Fortaleza, State of Ceará, in the first semester of 2020. Results: Collaborative actions, cooperation and effective communication among nursing and medical team contribute to the management of mild and complex cases of COVID-19, as well as qualify them in suitable and necessary care and confrontation measures. Final considerations: The report shows the need for collaborative practices to minimize negative effects on the population in the face of the new coronavirus pandemic.

Descriptors: Interdisciplinary Practices; Nursing Team; Patient Care Team; Emergencies; Coronavirus Infections.

\section{RESUMO}

Objetivo: Relatar a vivência de práticas colaborativas no enfrentamento da pandemia de COVID-19. Métodos: Trata-se de um relato de experiência acerca das práticas colaborativas das equipes de saúde nos cuidados emergenciais em Unidades de Pronto Atendimento diante da pandemia de COVID-19 em Fortaleza, Ceará, no primeiro semestre de 2020. Resultados: Ações de colaboração, cooperação e de comunicação efetiva entre equipe de enfermagem e equipe médica contribuem para manejo de casos leves e complexos de COVID-19, bem como qualificam-se em medidas de cuidados e enfrentamentos adequados e necessários. Considerações finais: $\mathrm{O}$ relato mostra a necessidade de práticas colaborativas para minimização de efeitos negativos na população diante da pandemia do novo coronavírus. Descritores: Práticas Interdisciplinares; Equipe de Enfermagem; Equipe de Assistência ao Paciente; Emergências; Infecções por Coronavírus.

\section{RESUMEN}

Objetivo: Relatar la experiencia de prácticas colaborativas en el enfrentamiento de la pandemia del COVID-19. Métodos: Se trata de una declaración de la experiencia referente a las prácticas colaborativas de los equipos de salud en los cuidados en emergencias en Unidades de Pronta Atención ante la pandemia del COVID-19 en Fortaleza, Ceará, en el primer semestre de 2020. Resultados: Acciones de la contribución, cooperación y de la comunicación efectiva entre el equipo de enfermería y el equipo médico contribuyen para dirigir los casos leves y complejos de COVID-19, así como se califican en medidas de los cuidados y enfrentamientos adecuados y necesarios. Conclusiones: La declaración muestra la necesidad de las prácticas colaborativas para disminución de los efectos negativos en la población ante la pandemia del nuevo coronavirus.

Descriptores: Prácticas Interdisciplinarias; Equipo de Enfermería; Equipo de Asistencia al Paciente; Emergencias; Infecciones por Coronavirus. 


\section{INTRODUCTION}

The COVID-19 pandemic is proving to be a worldwide complex public health challenge, affecting several countries on five continents and causing serious social, political, economic, religious, cultural and health consequences ${ }^{(1)}$. Considered an emergency, with 11.500 .302 cases and 535.759 deaths by July 7,2020 , it represents a major challenge for the current health systems $\mathrm{s}^{(2)}$. In Brazil, 1.755 .779 cases and 69.184 deaths were confirmed by July $7,2020^{(3)}$.

Meanwhile, there is an increasing need for trained and effective professionals to deal with the health services demands. However, the hegemonic formative model guiding Brazilian health care follows unidisciplinary and uniprofessional characteristics, submitting itself to regulations for professions intended to entry in the job market reserve, focusing on physiopathological conceptions of life, isolated practices that do not contribute to team action and with health care hierarchization ${ }^{(4)}$.

In 1998, the World Health Organization, the Pan American Health Organization, universities and researchers proposed modifications to the health care training models, pointing to interprofessional education (IPE) as a method for developing collaborative skills that maximize the effectiveness and quality of health care. IPE conceptually involves integrated and interactive learning between two or more health professions, allowing specific understanding of the role of each professional and enhancing collaborative skills for teamwork ${ }^{(4)}$.

The Interprofessionality as a modifying mechanism of health care team practices involves effective communication actions, participation in decision making, cohesion, coordination of services and problem solving, and it is recognized that the lack of those factors diminishes the effectiveness of the results. In the United States, a review of 23.000 allegations of neglect highlighted poor communication as one of the main components responsible for the inadequate functioning of a health care team, resulting in a cost of US\$ 1.7 billion and loss of about 2.000 lives $^{(5)}$.

Therefore, emergency facilities are dynamic spaces that treat high complexity patients, consisting to be high-risk locations in the eventuality of mistakes. The global panorama of overcrowding, extended period of time in units due to lack of stay beds and/or to get attendance care are situations that can compromise the quality of services, in which communication, cooperation and coordination are essential skills for improvement and effectiveness of health care ${ }^{(6)}$. Furthermore, they are one of the main services used as a gateway to the health system at this critical time of pandemic and represent an important ally in the development of health care and assistance to patients at risk of life.

In this sense, the current situation facing the COVID-19 pandemic involves the advance of interprofessional skills to meet the increasing demand of contaminated patients, and also highlighting the control of conflicts, intra-nursing team problems and interaction with the health care team, in addition to the patient care management. There is a need for the development of studies to feature improvements in the current health situation in light of collaborative health practices, interdisciplinarity and interprofessionality.
Consequently, there is a worldwide increasing need for the development of complex practices that are based on interdisciplinarity and interprofessionalism in order to achieve quality results in health care, through collaboration among professionals and expansion of interdisciplinary health care model $s^{(4-6)}$. Furthermore, there is an increasing perception that unidisciplinarity achieves ineffective results in front of the complexity of the health process and the illness of communities and population ${ }^{(4)}$.

Based on that premise, the expansion of health systems requires the development of health practices based on an interdisciplinary vision to solve problems, with effective results directed to the dynamics of health work actions and management of illness situations ${ }^{(5-6)}$. Nursing as a profession related to team and intrateam interaction and collaboration, as well as linked to the building of theoretical-practical models of health care, has been expanding actions through interdisciplinary and interprofessional actions with health teams contributing to modify community health realities ${ }^{(7)}$

\section{OBJECTIVE}

Report the experiences of collaborative practices in facing the COVID-19 pandemic.

\section{METHODS}

This is an experience report about collaborative practices of emergency health care teams working in Primary Health Care Unit (UPA) in the face of the COVID-19 pandemic in Fortaleza, Ceará. These health services network are health institutions which forms the Urgency and Emergency Network (RUE), defined as pre-hospital emergency and emergency care units ${ }^{(6)}$.

The report is conducted by emergency nurses working in two Primary Health Care Units (UPA) from March, 20 to April 28, 2020, which is the current time of reporting.

The Primary Health Care Units (UPA) described are secondary level services located in a socially and economically vulnerable region in the city of Fortaleza, both in the coastal area of the city. They present similarities in relation to the health professional team, practices and care developed, sheltering administrative services and clinical support such as laboratory and sterilization material center, urgency and emergency services, medical offices, medication administration room, emergency room for patients with clinical instability and stay beds to await transfer to support hospitals. The report describes the daily services providing aid in the face of COVID-19 in Brazil and especially in the state of Ceará, which concentrates most of confirmed cases in the Northeast region of the country.

The categories were established by analysis during the assembly of the results followed by an adaptation of Minayo's thematic analysis ${ }^{(8)}$. By producing the reports, it was observed the central themes that stood out the most, forming the core of the experience, and subsequently the themes presented in the results were described.

Next, it will be described how the pandemic of the new coronavirus in the state of Ceará has being confronted from the perspective of these locus of health care. 


\section{RESULTS}

Collaborative practices based on communication and professional interaction as a mechanism of care for positive COVID patients

Initially, the configuration of patient care changed with the new routine resulted from the COVID-19 pandemic, prioritizing the care for users who arrived in the sector with flu syndrome, characterized by fever, dry cough, coryza and dyspnea with oxygen saturation (SatO2 $>92 \%$ ). After risk classification, the specific medical professional in the office was communicated through alphabetic coding SG (flu syndrome), and the patient was isolated in the unit, if necessary.

Similarly, patients with severe acute respiratory failure (SatO2 < $92 \%$ ) were moved to the emergency room for appropriate oxygen therapy according to their clinical instability. In this sector, the unit assumed a new configuration, where stay beds were available for positive COVID patients and for negative COVID patients, in order to keep the isolation from those cases and the health care teams that took care of both flows. The following figure exemplifies the flowchart of treatment:

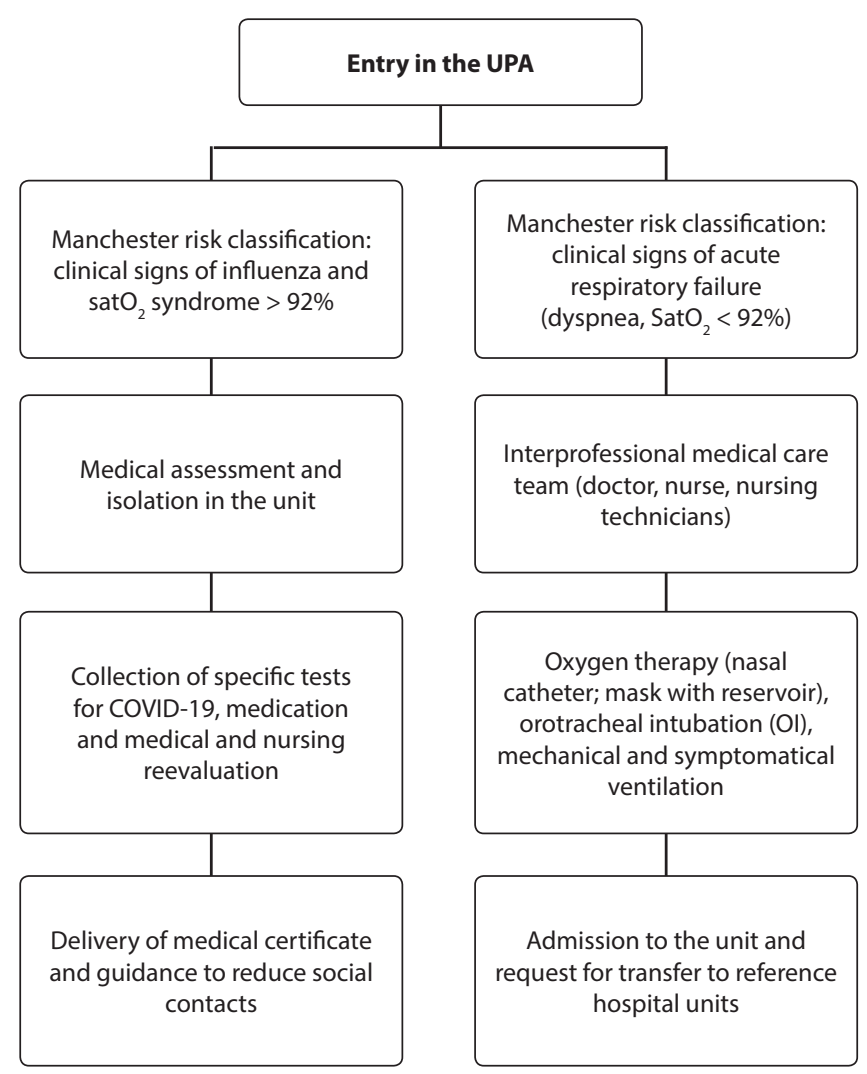

Note: UPA - Emergency Care Units.

Figure 1 - Unit's Health care flowchart for cases of influenza syndrome, Fortaleza, State of Ceará, 2020

In order to carry out the changes in the assistance configuration, simulated trainings were undertaken in the unit involving medical and nursing staff about the adequate placement of individual protection equipment (IPE), orotracheal intubation (OTI) and mechanical ventilation, as well as procedures in front of cardiac arrests in suspicious patients.
In this perspective, the change in the organized care flow approached in a collective way proposes to expand the collaborative actions among the medical and nursing team to a professional integration as a single health team directed to specific care for patients with COVID-19. That way interaction and effective communication in this phase were the basis for the action of the support team, mainly, to reduce the risk of contamination within the unit and carry out measures of aid and coordination among health professionals. The cooperation among professionals is an important modifying factor presented in the care actions.

The area of nursing presents itself as an outstanding profession for strengthening collaborative interprofessional practice and teamwork through its form of communication with the other components of the health team, promoting harmony, quality in decision making and impacting patients directly with quality care $^{(7-8)}$. Teamwork skills such as communication, respect, trust, mutual knowledge, collective power, centralization of actions on the patient, characteristics of the tasks and the environment were practices used during the crisis of the COVID-19(9).

In such a context, interprofessional cooperation among categories emerges as a response to the reality of the worldwide health situation which requires new assisting models to deal with the multiplicity of individuals with chronic diseases and with multi-morbidities, through the performance of nurses with skills in advanced practices, doctors, social workers and pharmacists. In Switzerland, a research using interviews with focus groups composed of general practitioners about the work with nurses showed little knowledge about their skills, but showed possibilities of intra-team cooperation ${ }^{(10)}$.

Therefore, multiprofessional teams unite workers who use specialized knowledge and juxtaposed disciplines, which can culminate in fragility in health care. Otherwise, interprofessional teams are based on problem solving, enhancing effectiveness and quality in care, providing the understanding of collaborative roles and skills for a teamwork ${ }^{(4,6-7)}$.

In view of this scenario, there is an increasing need for the evolution of multiprofessional teams into interprofessional ones, as well as the assimilation of concepts of interprofessional collaboration and collaborative interprofessional practices to improve access to and quality of health services and health care. Among the positive points of this practice it can be highlighted the improvement of the patient's and family's experience in health care, as well as advantages in the cost-effectiveness of health care ${ }^{(5)}$.

\section{Interprofessional education as a tool for training the health care team in the complex treatment of critically ill patients with COVID-19}

The last few weeks have required from nurses, nursing technicians and doctors working in Primary Health Care Units (UPA), hospitals and other services, perspectives and feelings of dedication, empathy, courage and resilience for the care of patients with suspicion or confirmation of COVID-19.

Nursing, as a professional category working in secondary care, utilizes leadership skills of the nursing team, association of scientific and technical knowledge to certify quality care and 
support the safety to the implementing body and health care users $^{(6-7,10)}$. In the current conjuncture, the Primary Health Care Unit (UPA) nursing team gathered the teams aiming to discuss the work processes to care for patients with suspicion or confirmation of COVID-19, focusing on the aid of those patients who arrive at the unit with respiratory failure requiring critical procedures such as OTI (Figure 1).

OTI is a procedure commonly performed by medical and nursing team, in which the patient requires invasive positive pressure ventilation for the treatment of several pathologies. In the case of COVID-19, the team needs safety measures to perform it, because professionals' risk of contamination becomes greater. This interaction was based on health teams training in care of patients with severe cases of COVID-19.

Within this interaction dynamic, the teams met on three alternate days at the beginning of each activity, emphasizing new models to face the pandemic, in the presence of medical professionals, nurses and nursing technicians. The objective of the inter-team meetings was to understand, in practice, that the processes of collaboration to aid patients with suspected COVID-19 were reorganizing and needed urgent improvements in the aspects of treatment.

In this context, the nursing and medical coordination developed training activities. The teams accepted well the participation, being involved and with professional collaboration, discussing amongst each other collectively and using videos to disseminate the new practices. The OTI's strategy was little questioned, because the training took place in a clear and objective manner, to the point that a few professionals reported their doubts in relation to the materials used and possible difficulties to carry it out, such as lack of supplies.

Thus, it was highlighted that for a successful OTI practice in patients with suspected COVID-19, the professionals directly acting on it should perform it emphasizing the action of the health team in a synchronized, collaborative manner, with dynamic and effective communication among the component categories. Also, the technical knowledge proved to be essential for a collaborative care in the health services.

Reports about the performance among medical and nursing teams demonstrate certain elements inserted in collaborative and interdisciplinary practices, such as communication between teams, mutual cooperation and collaboration to achieve goals, which are quality in health care and assistance to contaminated patients ${ }^{(4-6,9)}$. Furthermore, simulation training aims at cooperation between health team professionals, decreasing risks and mistakes during protective and complex procedures.

In the meantime, several factors may contribute to or hinder interprofessionalism, such as: commitment of professionals to interprofessional practice directed at the patient; and the existence of tensions related to the perception of unequal voice and power among categories ${ }^{(9)}$.

However, in the face of the new coronavirus pandemic, interaction among professionals is being developed in a positive way, reframing collaborative action among health teams, based on daily changes in flow and services, as well as professional practices and interprofessional relationships among teams. To illustrate the collaborative practices, it was designed the following Figure 2:

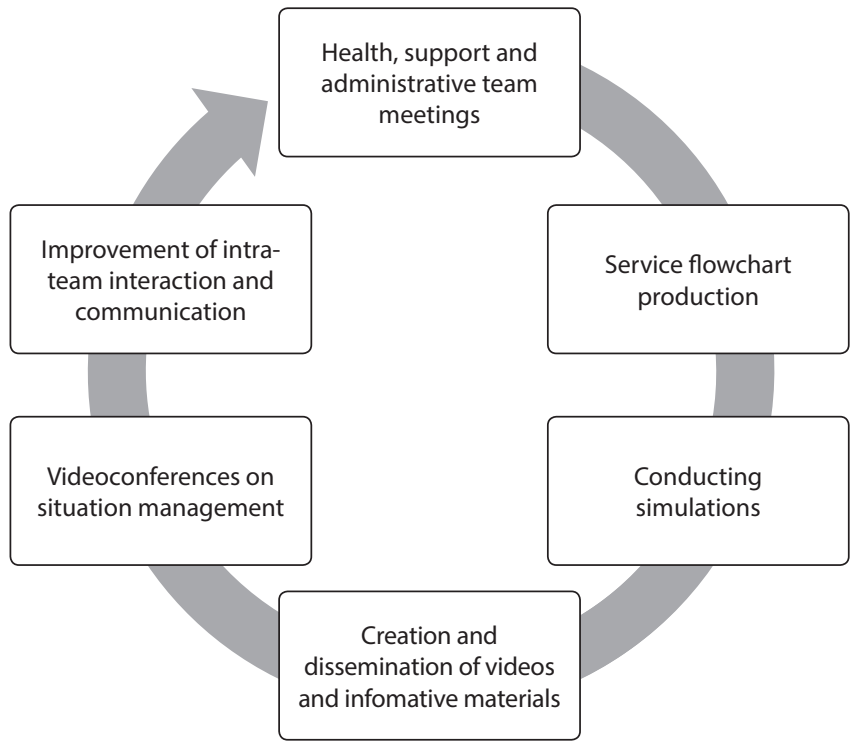

Figure 2 - Collaborative practices at the Emergency Care Units to address the pandemic of COVID-19, Fortaleza, Ceará, 2020

As demonstrated in Chart 2, a cycle of activities was performed aiming at continuous improvement in the care of positive COVID patients, and it was routinely done on certain days. Training and simulations on OTI and cardiopulmonary resuscitation were performed on Tuesdays; and videoconferences on the use of mechanical ventilator and changes in the services flowchart, on Thursdays or Fridays, depending on the availability of the medical and nursing coordinators who assumed the responsibility of leading at the moment.

The non-interaction among teams, a gap in behavior among the professionals and ineffective communication can bring highly negative outcomes in the face of the COVID-19 pandemic, increasing health system costs, morbidity and mortality, hindering the mood and interaction among the health team and bringing about a gap in the line of health services and work management ${ }^{(4-10)}$.

The development of collaborative practices described has helped strengthen communication within the health care team and enabled interaction through the building of services and health care flows, creation of training videos on social networks and internet applications, as well as training simulations and consensus-building meetings.

\section{Study limitations}

The limitation in this experience report consists of the short period of time before the confrontation of COVID-19, as well as the singularities arising from an assistance with protocols that are still poorly defined and from which health professionals obtain little information for the development of their activities.

\section{Contributions to the Nursing field}

The manuscript focuses on interprofessionality and interdisciplinarity through collaborative practices as an instrument to strengthen the performance of the health team and improve the quality of health services in light and severe conditions of 
the disease, demonstrating through reports the improvement of health activities.

\section{FINAL CONSIDERATIONS}

The study portrayed the experiences of the health team formed by doctors and nurses in the development of collaborative practices to confront the COVID-19 pandemic in the state of Ceará, emphasizing communication, interaction and cooperation to enhance the dynamics and quality of health care services.

The restructuring of health actions proved to be challenging, requiring interconnection between care services and health management, organization of human resources, supplies and technologies, use of epidemiological indicators and flowcharts, interprofessional actions in critical health care services, intersubjectivity in patient assistance, indicating interdisciplinary principles to face the pandemic of the new coronavirus.

In this experience, it became evident that collaborative team practices were relevant in organizing those teams who were facing stress in emergencies, fear of contamination and conflicts. Nursing as a profession related to health care services must amplify its interrelationships with the health team to improve the quality of health care services and limit delays and mistakes.

\section{REFERENCES}

1. Jakovljevic M, Bjedov S, Jaksic N, Jakovljevic I. Covid-19 pandemia and public and global mental health from the perspective of global health security. Psychiatr Danub. 2020;32(01):6-14. doi: 10.24869/psyd.2020.6

2. Organização Mundial da Saúde. Folha informativa - COVID-19 (doença causada pelo novo coronavírus) [Internet]. 2020 [cited: 2020 Apr 25]. Available from: https://www.paho.org/bra/index.php?option=com_content\&view =article\&id=6101:covid19\&ltemid=875

3. Ministério da Saúde (BR). Painel Coronavírus [Internet]. [cited: 2020 Jul 08]. Available from: https://covid.saude.gov.br/

4. Lima AWS, Alves FAP, Linhares FMP, Costa MV, Marinus-Coriolano MWL, Lima LS. Perception and manifestation of collaborative competencies among undergraduate health students. Rev Latino-Am Enfermagem. 2020;28:e3240. doi: 10.1590/1518-8345.3227.3240

5. Kilpatrick K, Tchouaket E, Paquette L, Guillemette C, Jabbour M, Desmeules F, et al. Measuring patient and family perceptions of team processes and outcomes in healthcare teams: questionnaire development and psychometric evaluation. BMC Health Serv Res. 2019;19:9. doi: 10.1186/s12913-018-3808-0

6. Batista REA, Peduzzi M. Interprofessional Practice in the Emergency Service: specific and shared assignments of nurses. Rev Bras Enferm. 2019;72(Suppl 1):213-20. [Thematic Issue: Work and Management in Nursing].doi: 10.1590/0034-7167-2017-0797

7. Sonke J, Pesata V, Lee JB, Graham-Pole J. Nurse perceptions of artists as collaborators in interprofessional care teams. Healthcare. 2017;5:50. doi: 10.3390/healthcare5030050

8. Minayo MCS. O desafio do conhecimento: pesquisa qualitativa em saúde. 14a ed. São Paulo: Hucitec; 2014.

9. Karama M, Braultb I, Van Durmea T, Macqa J. Comparing interprofessional and interorganizational collaboration in healthcare: a systematic review of the qualitative research. Int J Nurs Stud. 2018;79:70-83. doi: 10.1016/j.ijnurstu.2017.11.002

10. Steinbrüchel-Boesch, C, Rosemann, T, Spirig, R. Neue Zusammenarbeitsformen mit Advanced Practice Nurses in der Grundversorgung aus Sicht von Hausärzten: eine qualitativexplorative studie. Praxis. 2017;106 (9):459-64. doi: 10.1024/1661-8157/a002658 